\title{
Design, Investigation and Measurement of A Compact Ultra Wideband Antenna for Portable Applications
}

\author{
Ahmed Toaha Mobashsher ${ }^{1}$, Mohammad Tariqul Islam ${ }^{2}$ \\ ${ }^{1}$ School of Information Technology and Electrical Engineering, The University of Queensland, St. Lucia, Brisbane, \\ QLD 4072, Australia, i_toaha@yahoo.com \\ ${ }^{2}$ Institute of Space Science (ANGKASA), Universiti Kebangsaan Malaysia, 43600 UKM Bangi, Selangor D., E., Malaysia, \\ titareq@yahoo.com
}

The design of a printed compact planar antenna of asymmetrical structure with ultra wide bandwidth is described and investigated in this paper. The antenna provides more than 114\% impedance bandwidth below VSWR 2 (from 3.3 to more than 12 GHz) with a center frequency of $7.65 \mathrm{GHz}$; thus it covers the bandwidth requirement for portable UWB wireless device applications. The structure of the asymmetric proposed antenna is very simple and composed of a small hexagonal shaped patch with two asymmetrical coplanar ground planes. It occupies an area of only $20 \times 24.5 \mathbf{m m}^{2}$ when printed on one side of an FR4 substrate with a thickness of $1.6 \mathrm{~mm}$.

Keywords: Antenna measurement, ultra wideband technology, radiation patterns measurement, compact antenna system, microwave frequencies, surface current distribution, portable device applications.

\section{INTRODUCTION}

$\mathrm{U}$ LTRA WIDEBAND (UWB) radio is one of the most emerging and promising wireless communication technologies that use ultra short impulse waveforms in the order of nanoseconds compressed in time rather than sinusoidal or modulated waveforms compressed in frequency. This is the prime difference between conventional typical narrow band systems and UWB systems. Also this time domain technique of UWB systems enables the transmission of a wide frequency spectrum in such a way that a very low-power-level spectral density can be successfully received.

UWB has become a prominent technology and attracted enormous attention in wireless sensing and imaging applications for its extremely high data rate and accuracy. The Federal Communications Commission (FCC) [1] authorized the unlicensed use of the 3.1-10.6 GHz spectrum for UWB applications with limited power spectral density emission. This power limitation enables spectrum sharing with other established narrowband applications without creating any mutual interference. In portable applications of UWB systems, the antennas mostly constrains the size of the whole device. Hence, the antennas are required to be compact, low-profile, and cost effective while presenting good pulse-preserving performance with stable channel transfer response and broad impedance bandwidth.

Printed planar antennas have drawn much attention owing to their simple structure, small size, low profile, and ease of implementation in fabricated portable devices. A doublesided planar antenna generally comprises of a monopole element and a finite ground plane on the opposite side of the monopole. Due to the large ground plane, typical geometry of the double-sided planar antenna can greatly increase [217]. Terminating a radiating element with coplanar waveguide (CPW) feeding is more advantageous than other feeding types like microstrip or probe feeding [18]. A CPW- fed antenna not only attains a broad bandwidth, but also develops a smaller mutual coupling between adjacent lines $[19,20]$. However, the existing CPW-fed antennas are not suitable for portable UWB applications due to their big profiles [20-30, 36]. Therefore, a wide field of research exists for the development of compact antennas with ultra wide bandwidth. Moreover, most of the CPW-fed antennas are symmetrical in design. Some asymmetric CPW-fed UWB antennas can also be found in reported literatures [3134], but they are either of complex structure or of big shape for portable device applications. The printed structures described in [38-42] provides ultra wide bandwidth with some advanced techniques, however, fails provide competitively compact size.

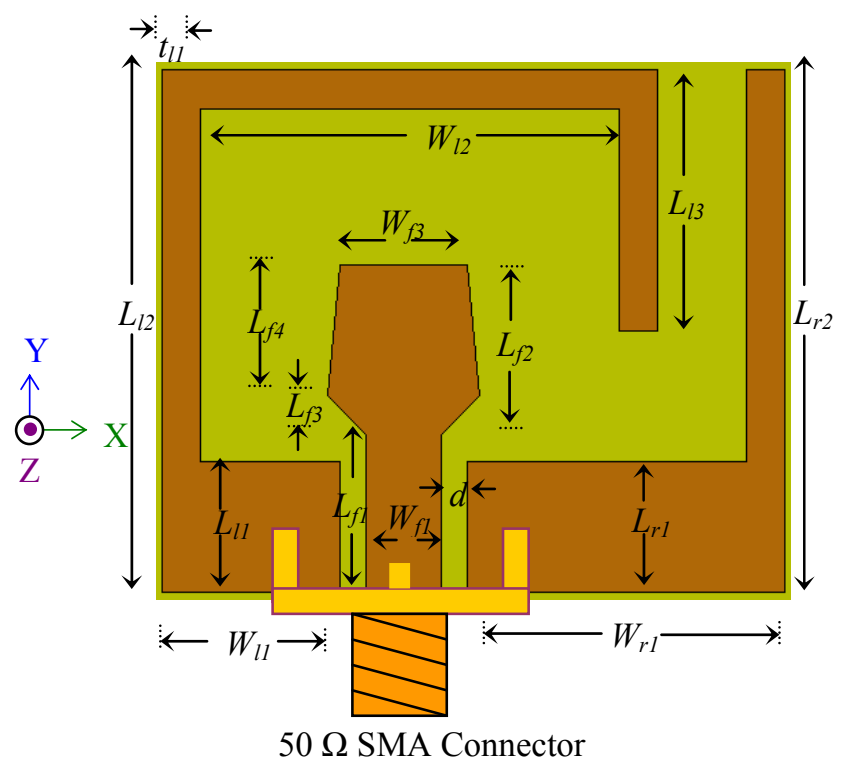

Fig.1. Design geometry and schematic diagram of the antenna. 


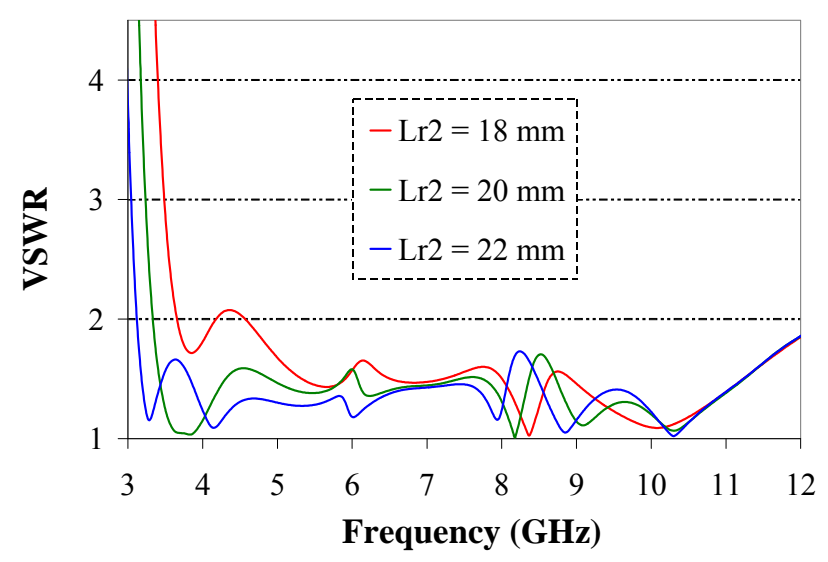

(a)

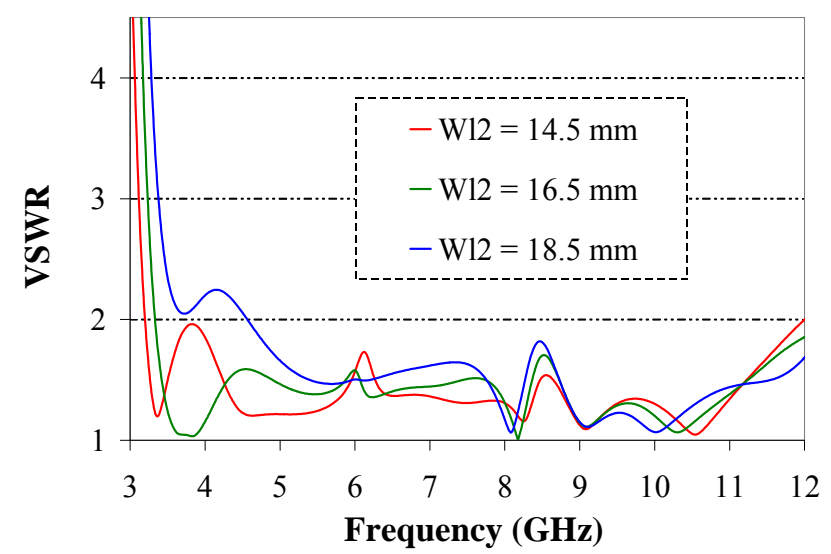

(b)

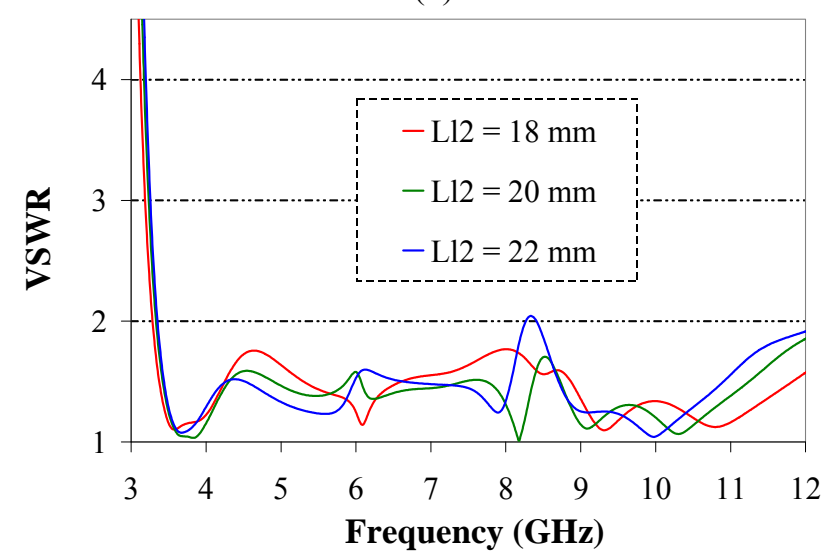

(c)

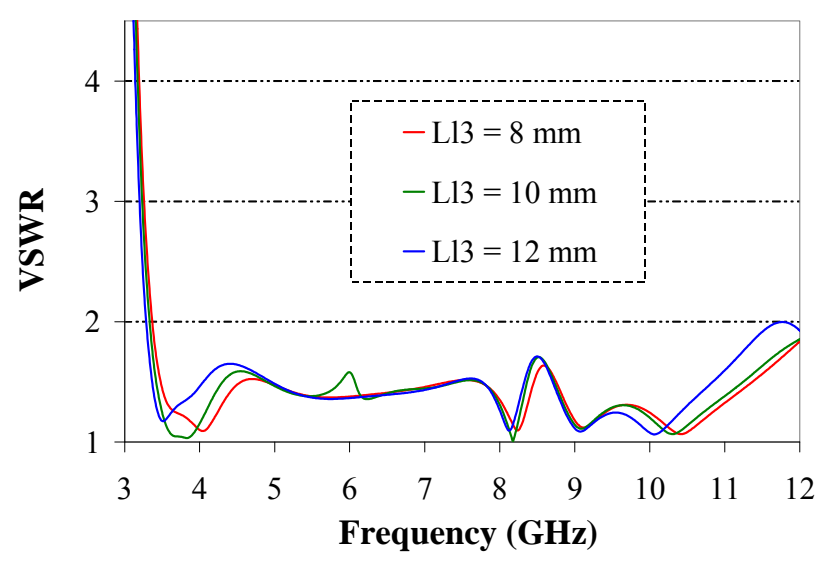

(d)

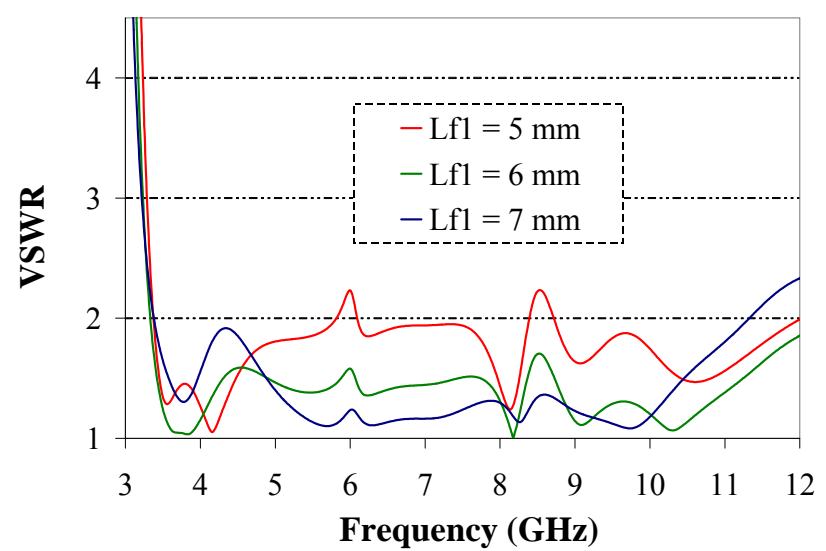

(e)

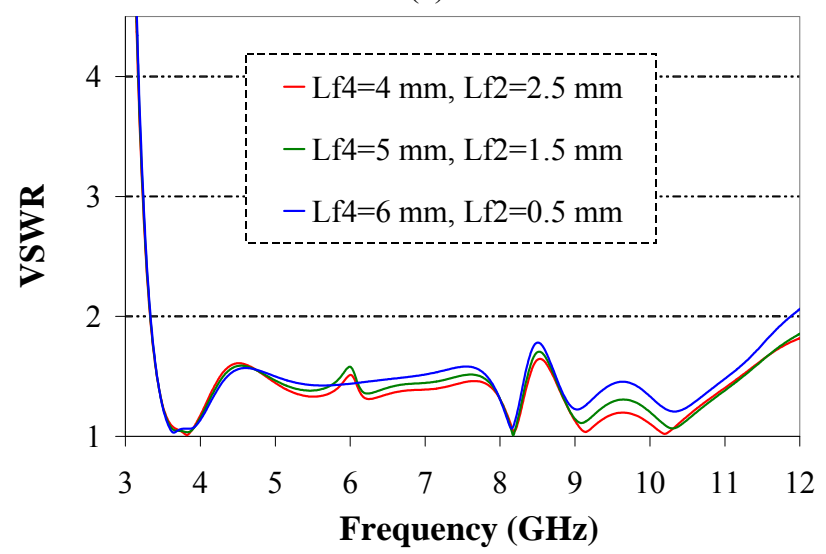

(f)

Fig.2. Effect on VSWR and resonant frequencies due to change of (a) $L_{r 2}$, (b) $W_{l 2}$, (c) $L_{l 2}$, (d) $L_{l 3}$, (e) $L_{f 1}$, (f) $L_{f 4}, L_{f 2}$.

In this paper, a compact asymmetric UWB antenna is projected for the portable device applications. The antenna covers more than $114 \%$ impedance bandwidth below VSWR 2, with monopole like Omni-directional stable radiation patterns and acceptable gains. The measured group delay, phase distribution and magnitude response of the antenna transfer function of face-to-face orientation in farfield are also presented in this paper. The layout of the paper is as follows. The antenna design and geometry, with a numerical parametric study describing the effects of various parts on the antenna performances, are discussed in Section II. In Section III, experimental and simulated results of the antenna are presented with detailed discussions. The acknowledgements from the authors are made in Section IV. The conclusions are presented in Section V.

\section{ANTENNA GEOMETRY \& DESIGN}

The schematic diagram of the proposed portable UWB antenna for wireless applications is illustrated in Fig.1. The antenna is printed on only one side of FR4 substrate $\left(\varepsilon_{r}=\right.$ 4.4 , thickness $\mathrm{h}=1.6 \mathrm{~mm}$ ) and no metal is utilized on the other side of the substrate, which is beneficiary for the compact devices especially for low cost wireless modules undergoing a mass production. 
A coplanar waveguide transmission line with a width of $W_{f l}$ and gap of $d$ is used to feed the antenna. A gap of $d$ is maintained between the strip line and the coplanar ground plane, from the both sides of the feeding strip. The values of the width, $W_{f l}$ and the gap, $d$ are chosen in such a way that the input impedance of the feeding of the antenna becomes equivalent to $50 \Omega$ for $1.6 \mathrm{~mm}$ thick FR4 substrate. The metallization used for the proposed design is of $1 \mathrm{oz}(35 \mu \mathrm{m}$ thick) copper cladding which is commercially available for the used substrate.

The antenna uses two partially radiating coplanar ground planes as primary source of radiation. These grounds also enhances the impedance matching of the antenna. Instead of using a complex matching circuit to achieve a wide bandwidth, the coplanar shape of the asymmetric antenna is fed by a simple SMA connector which is self resonating with a very small size. The vertical modified-bow-tie shaped radiator with unequal wings is the basis of the antenna structure. The radiating element has the total length of $L_{f 2}$. The tapered transitional length of the lower wing is $L_{f 3}$, which is $W_{f 2}$ wide; while the length of upper wing is $L_{f 4}$ and its final breadth is $W_{f 3}$. At the end of the long CPW feed line, $L_{f 1}$ the lower wing is connected. The ground planes cover the radiating element like arms from the both sides and are asymmetric with respect to each other. An inverted L-shaped ground plan is positioned at the right side of the radiator, which comprises two vertical and horizontal parts with dimension of $W_{r l} \times L_{r 1}$ and $t_{r 1} \times L_{r 2}$. These two parts has overlapped on an area of $t_{r l} \times L_{r l}$. On the left side the Ushaped ground plane has a length of $L_{12}$ and the dimensions of upper and lower arm are $W_{l 2} \times t_{l 2}$ and $\left(W_{l 1}-t_{l 1}\right) \times L_{l 1}$ respectively.

The parametric studies of the various antenna parameters plotted in Fig.2. exhibit the design procedures followed to optimize the proposed UWB antenna. The vertical length of the inverted L shaped ground, $L_{r 2}$ and the length of the upper horizontal arm of U-shaped ground, $W_{12}$ have a significant effect on lower resonance. Increasing the values of these parameters increases the current path of the antenna that consequently shifts the cutoff frequency to some lower value and vice versa. But increasing the value of $L_{r 2}$ (Fig.2.(a)) increases the antenna profile. As exhibited in Fig.2.(b), the increment of $W_{l 2}$ simultaneously decreases the higher cutoff frequency and increases nulls in VSWR curve. However, as seen from Fig.2.(c) and (d), the vertical parts of the U-shaped ground, $L_{l l}$ and $L_{l 3}$ define the higher cutoff frequency with a slight variation in the lowest resonance. In case of the CPW-fed radiating patch, it is important to optimize the feeding line, since from Fig.2.(e) it is evident that variation in $L_{f l}$ is vital for the proposed antenna design. Nevertheless, the patch dimension, $L_{f 2}$ and $L_{f 4}$ can be used (as shown in Fig.2.(f)) to optimize the higher resonating frequencies. From these studies it can derived that the Ushaped ground plane plays most important role on both the lower and higher resonating frequencies of the proposed broadband antenna.

The total dimension of the UWB antenna is optimized to a compact size of $20 \times 24.5 \mathrm{~mm}^{2}$, which is smaller than other existing antennas of the literature [20-34, 38-42] and is suitable for the applications in portable devices. In order to achieve the wideband operations and performance investigation of the proposed antenna configurations a fullwave, method-of-moment (MoM) code based commercially available electromagnetic simulator Zeland IE3D version 12 is used. The software is also utilized to probe down the required numerical analysis to obtain the proper geometrical parameters shown in Fig.1. The determined optimal dimensions are listed in Table 1. The simulated design of the compact UWB antenna is prototyped for the substantiation and an Agilent E9362C network analyzer is utilized for the evaluation. The measured results are observed to agree with the simulated ones. The photograph of the prototype is presented in Fig.3.

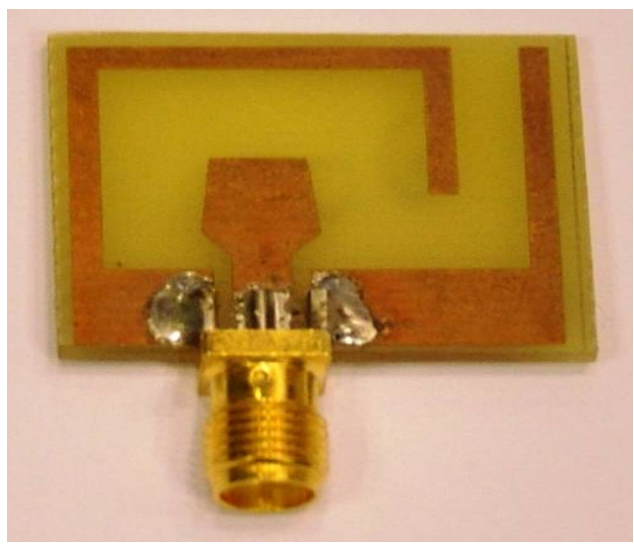

Fig.3. Photograph of the prototyped antenna.

Table 1. Designed parameters for the geometry of the proposed antenna.

\begin{tabular}{|l|l|}
\hline Parameters & Value in $\mathbf{~ m m}$ \\
\hline$\left\{W_{f 1}, L_{f 1}\right\}$ & $\{3,6\}$ \\
\hline$\left\{W_{f 2}, W_{f 3}, L_{f 2}, L_{f 3}, L_{f 4}, d\right\}$ & $\{1,5,6.5,1.5,5,1\}$ \\
\hline$\left\{W_{l 1}, W_{l 2}, L_{l 1}, L_{l 2}, L_{l 3}, t_{l 1}\right\}$ & $\{7,16.5,5,20,10,1.5\}$ \\
\hline$\left\{W_{r 1}, L_{r 1}, L_{r 2}\right\}$ & $\{12.5,5,20\}$ \\
\hline
\end{tabular}

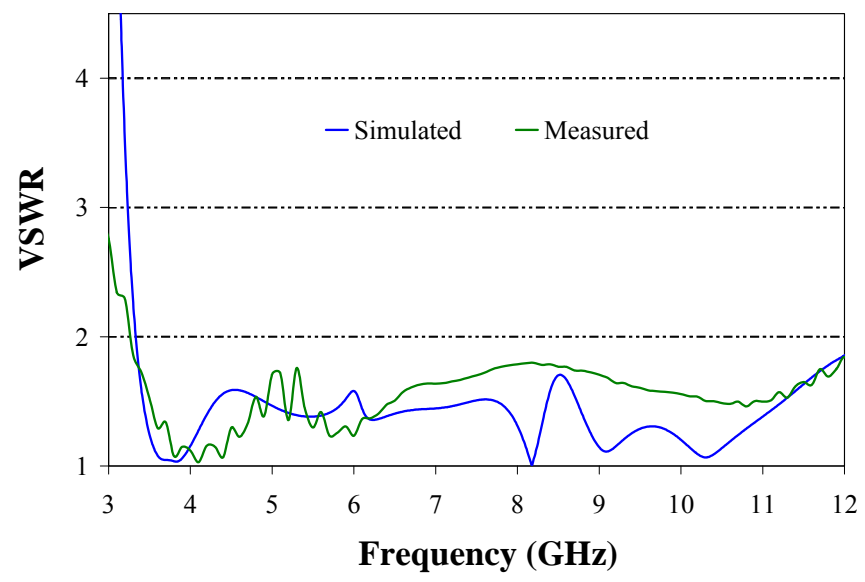

Fig.4. Measured and simulated VSWR of the proposed antenna. 


\section{RESULTS \& DISCUSSIONS}

The measured and simulated voltage standing wave ratio (VSWR) of the prototyped antenna are shown in Fig.4. The return loss of the antenna is also exhibited in Fig.5. Return loss of $-10 \mathrm{~dB}$ which is approximately equivalent to VSWR 2 is taken as the reference level of the measured values. The proposed antenna produces a wide bandwidth of more than 8.7 GHz, covering from $3.3 \mathrm{GHz}$ to more than $12 \mathrm{GHz}$ beneath the VSWR 2 level. The equivalent fractional bandwidth is approximately $114 \%$ with the center frequency at $7.65 \mathrm{GHz}$. However, a bandwidth of more than $8.6 \mathrm{GHz}(111 \%, 2 \geq \mathrm{VSWR})$ ranging from about $3.4 \mathrm{GHz}$ to more than $12 \mathrm{GHz}$ is obtained in simulation. Differences between the simulated and measured results might be caused by the fabrication and measurement inaccuracies of the prototype. Also the simulated antenna is fed by a lump port that is considered to be loss-less and of $50 \Omega$ for the wide range of frequencies, which is difficult to attain in fabrication especially for the low cost materials. Deviation from simulation results might also be caused for practical SMA connector implementation. Nevertheless, a relatively long co-axial cable is used in measurement to connect the antenna with the network analyzer. Hence the sharp ripples (more than $5 \mathrm{~dB}$ ) in lower frequencies are observed. These ripples are caused by the current drain from the ground plane of the antenna to the outer shield of co-axial cable, which is not presumed in simulation.

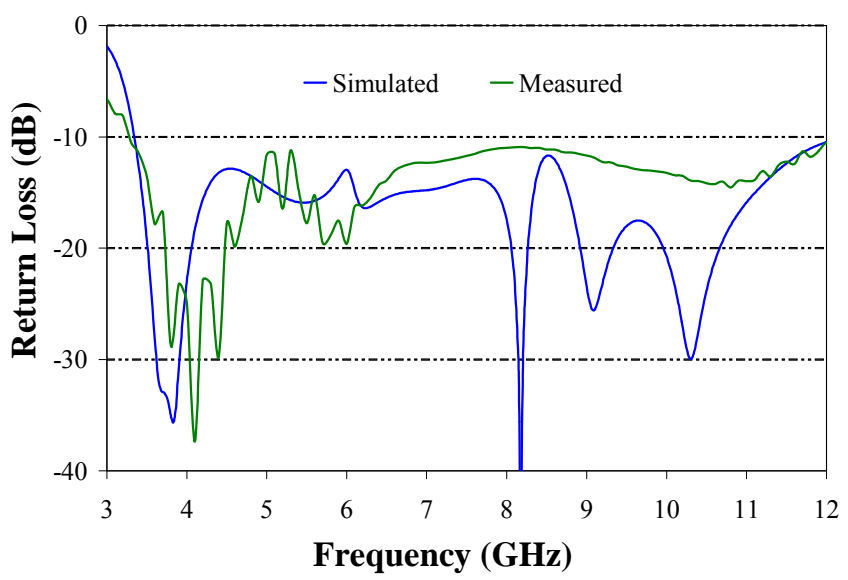

Fig.5. Measured and simulated return loss vs. Frequency of the proposed antenna.

The MoM-based electromagnetic simulator IE3D is used to observe the excited surface current distributions of the proposed antenna at 3.5, 5, 6, 6.5, 8, 9.5, 11 and $12 \mathrm{GHz}$. They are respectively presented in Fig.6. The arrows show the direction of the current paths and the color scale represents the current intensity on the antenna surface. The blue color region shows the null current at that portion of antenna in that particular frequency. Comparing with higher resonances, the current distributions are more intense on the horizontal ground portion (X-direction) at the lower ones. Stronger current distribution is observed in X-direction of the antenna which gradually decreases with the increase of operating frequency. This is one of the reasons to develop high cross-polarization level in H-plane [20, 36], which is explained later in detail. The small $\mathrm{CPW}$-fed radiating patch and the feeding line perform a significant role in $\mathrm{Y}$ directional current distribution. Because of this significant current distribution, the E-plane radiations have higher copolarization level.
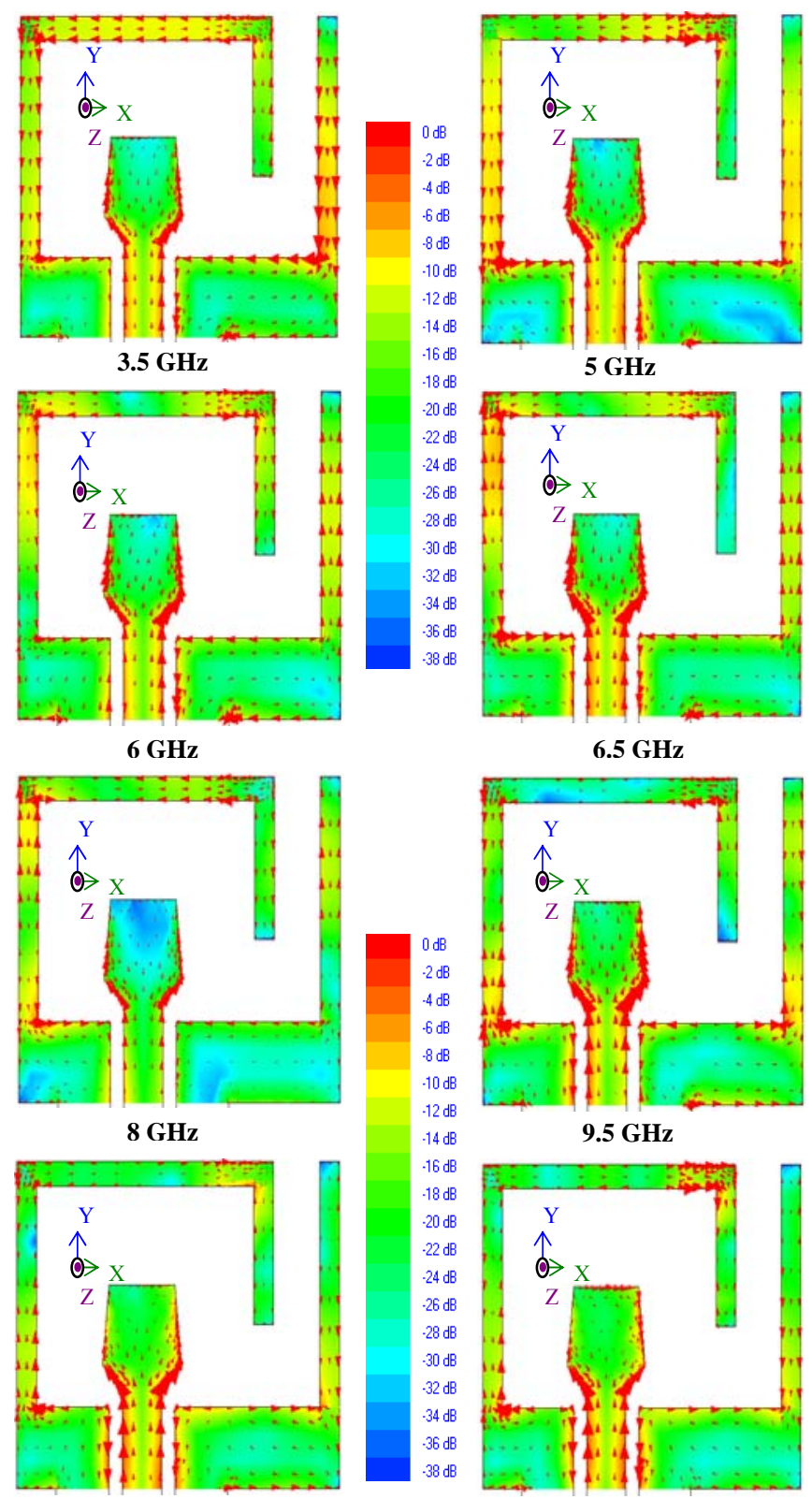

$8 \mathrm{GHz}$

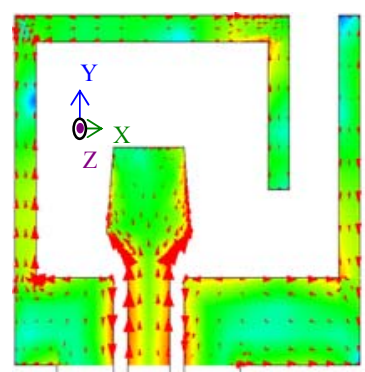

$14 \mathrm{~dB}$
$.16 \mathrm{~dB}$
$-18 \mathrm{~dB}$
$.20 \mathrm{~dB}$
$.22 \mathrm{~dB}$
$.24 \mathrm{~dB}$
$.26 \mathrm{~dB}$
$.28 \mathrm{~dB}$
$.30 \mathrm{~dB}$
$.32 \mathrm{~dB}$
$.34 \mathrm{~dB}$
$.36 \mathrm{~dB}$
$.38 \mathrm{~dB}$

$11 \mathrm{GHz}$

$12 \mathrm{GHz}$

Fig.6. Surface current distribution of the proposed antenna in various frequencies.

The radiation patterns of $\mathrm{E}$ and $\mathrm{H}$-plane of the proposed antenna at $3.5,5,6,6.5,8,9.5,11$ and $12 \mathrm{GHz}$ are exhibited in Fig.7. \& 8. It is observed that the patterns demonstrate a slightly deviated Omni-directional radiation of the UWB antenna. Despite the asymmetrical structure of the designed UWB antenna, almost symmetrical radiation patterns with distorted ripples in some lobes are found in measurement. 
The Omni-directional radiation pattern presents a significant advantage for the portable devices, as they achieve surround coverage for the wireless connectivity with other devices or systems. Nevertheless, comparing with other reported asymmetric CPW-fed UWB antennas [3-34] the proposed antenna provides smooth and less-rippled radiation patterns; even in the high frequencies. This is because in higher frequencies, maximum currents are seen to be concentrated along the central-fed radiator.

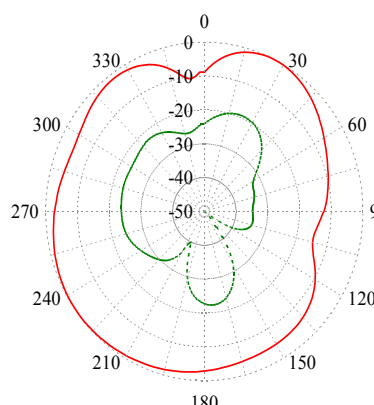

$3.5 \mathrm{GHz}$

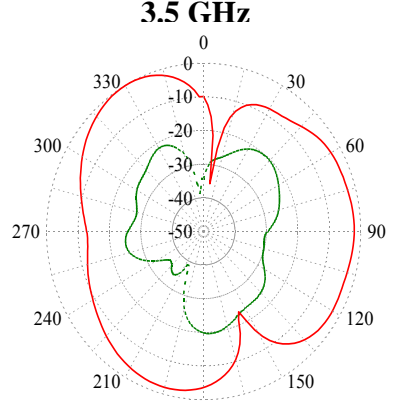

180
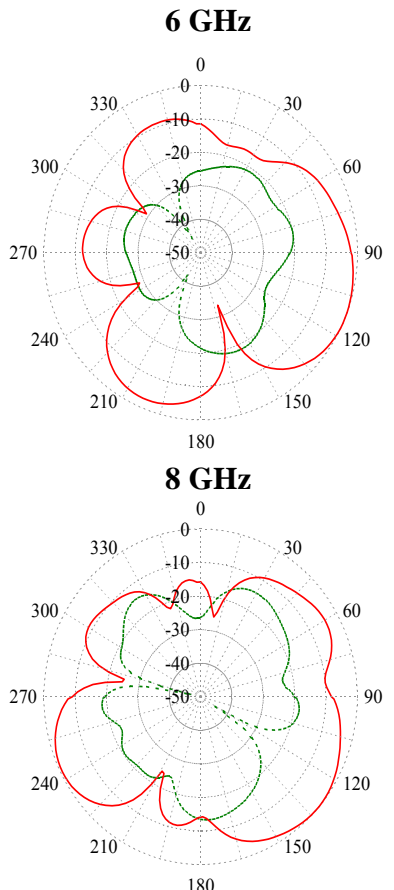

$11 \mathrm{GHz}$

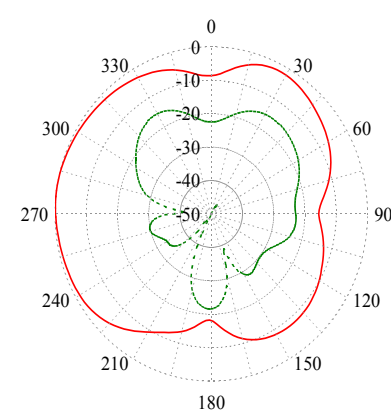

$5 \mathrm{GHz}$

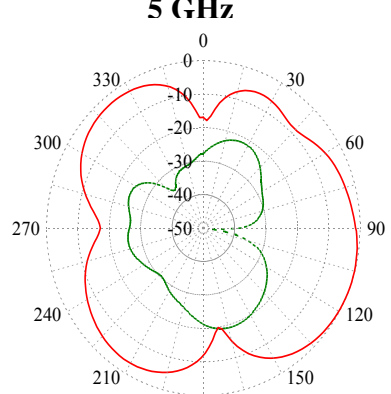

180
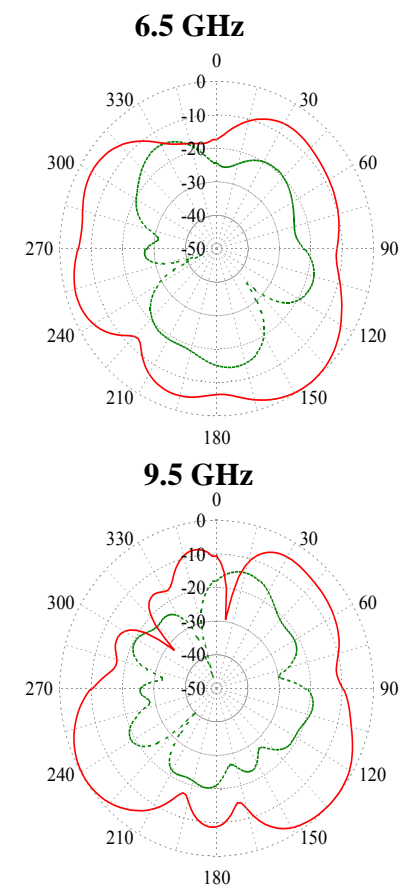

$12 \mathrm{GHz}$
Fig.7. Measured radiation pattern of the proposed antenna at various frequencies on E-plane.
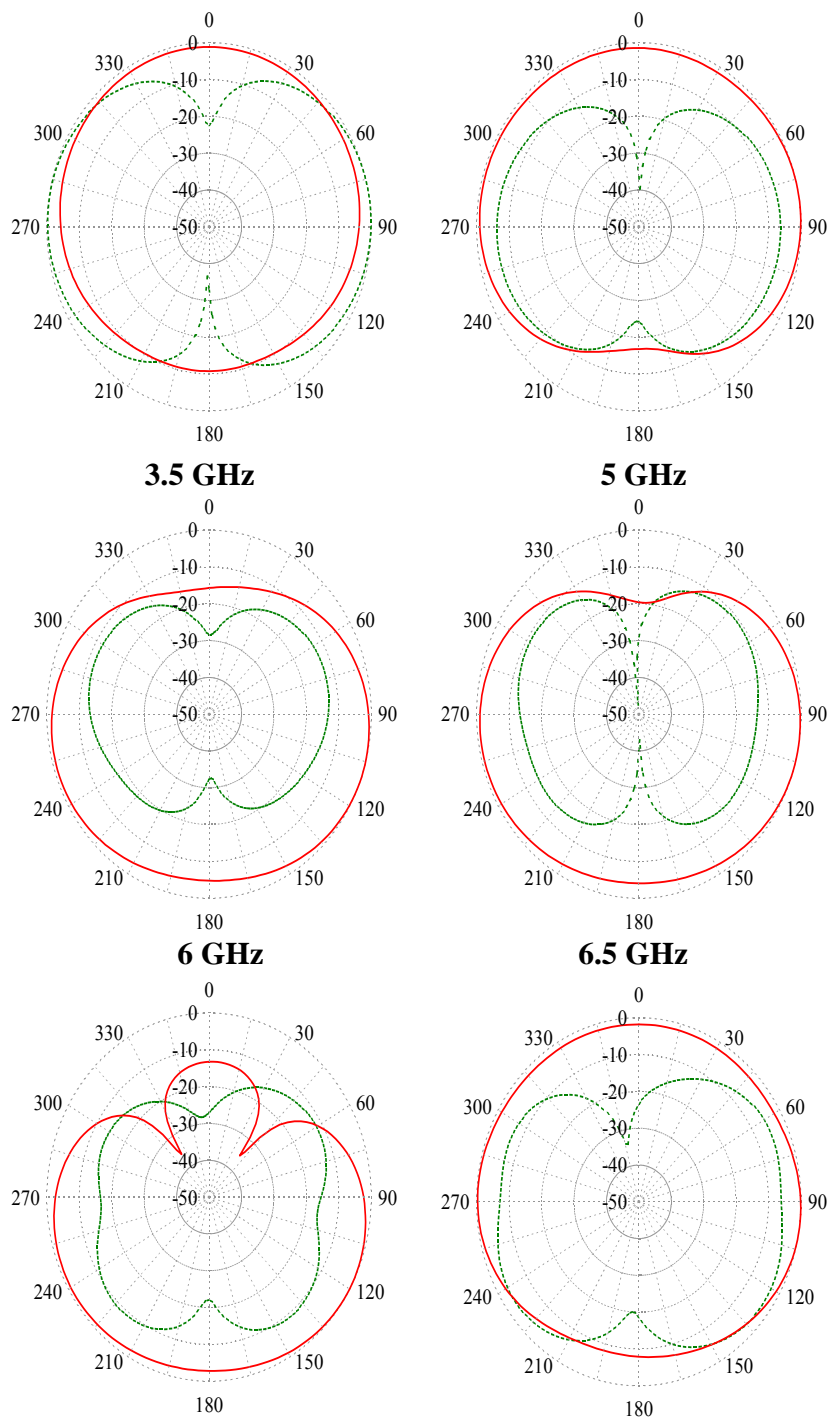

180

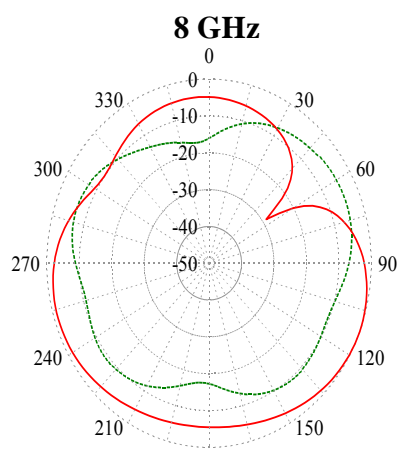

180

$11 \mathrm{GHz}$

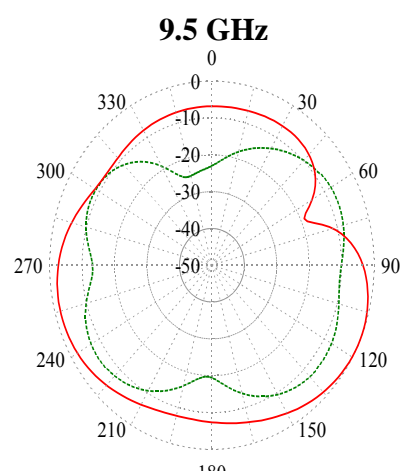

180

$12 \mathrm{GHz}$
Fig.8. Measured radiation pattern of the proposed antenna at various frequencies on $\mathrm{H}$-plane.

The cross polarization level of the UWB antenna is higher in H-plane (XZ-plane) radiation patterns, especially at the lower frequencies. This can be attributed to the strong horizontal components of the surface currents. The vertical components (in Y-direction) of the surface currents are the main contributors of the radiation. But the currents along the horizontal section of the ground plane (in X-direction) do 
not contribute to the co-polar radiation in the H-plane; instead they cause high cross-polarization [20,36]. The radiation of the antenna is still reasonably better in the desired Z-direction $\left(90^{\circ}, 270^{\circ}\right)$. However, in higher frequencies, since the currents in X-direction decrease and as the relative antenna size increases in comparison to wavelength, the cross polarization level goes lower. In case of the E-plane (YZ-plane) radiation patterns, the cross polarization of the proposed antenna is quite low and the main lobes are directed to the desired Z-direction $\left(90^{\circ}\right.$, $270^{\circ}$ ) which can be vital for the portable devices in order to avoid the interferences of the other antenna radiations.

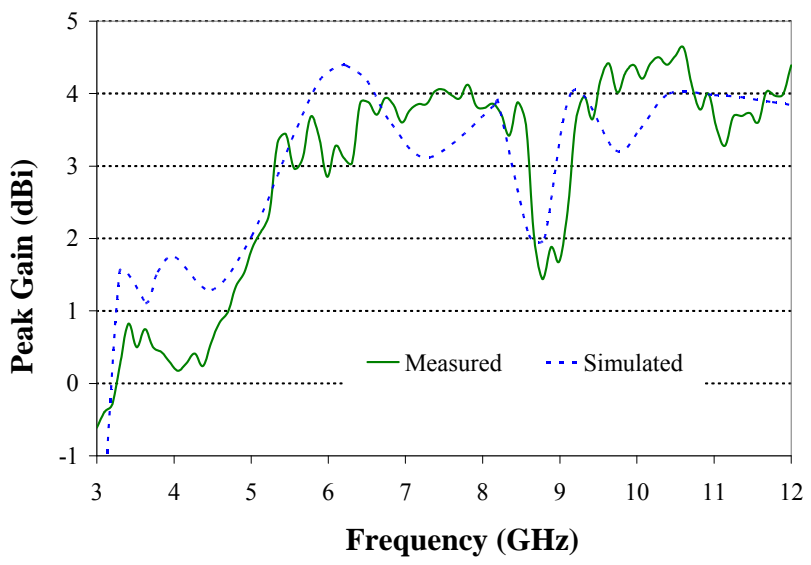

Fig.9. Measured and simulated gain comparison of the antenna.

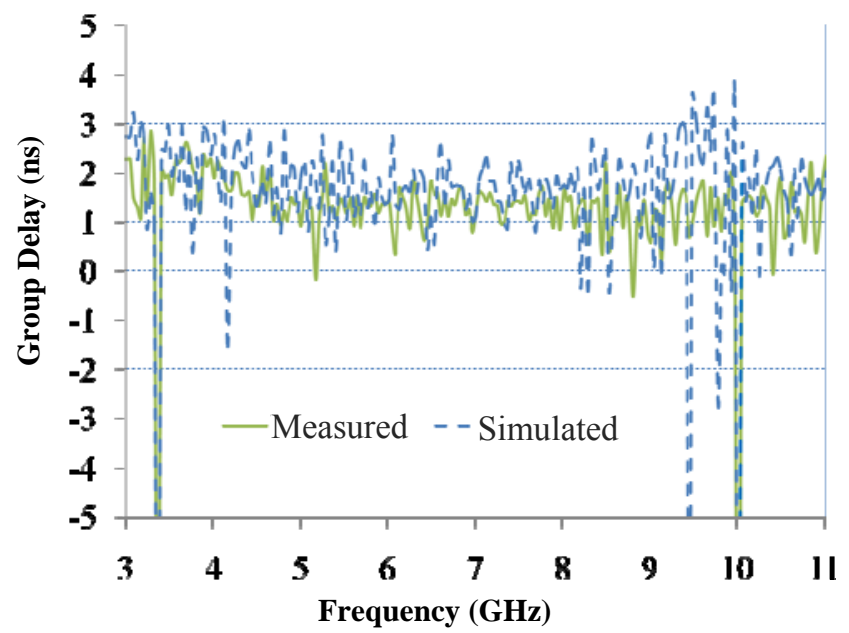

Fig.10. Measured and simulated group delay comparison of the transfer function.

Peak antenna gain of the antenna over the whole UWB band is illustrated in Fig.9. As expected, the antenna gain increases with the increase of the operating frequencies. Measured gain of the antenna matches quite well with the simulated one. The maximum antenna gain of $4.5 \mathrm{dBi}$ is achieved at approximately $10 \mathrm{GHz}$. However, the antenna attains an overall gain of more than $0 \mathrm{dBi}$ over the entire bandwidth. Since the antenna would be used for the short range communication purpose, this peak gain is in the acceptable range. Low loss Duroid Substrate is suggested in order to increase the gain of the proposed antenna. However, the use of this substrate increases the cost of the antenna and hence this option is not chosen for the design.

A null in the gain plot is observed around $9 \mathrm{GHz}$ which is primarily for the measurement limitations. Around $9 \mathrm{GHz}$, the SMA connector have a degenerative effect on the small monopole antenna, since around that frequency the dimension of SMA connectors gets closer to a quarter of the guided wavelength of the operating frequency ( $\lambda_{g}=\lambda_{o} / \sqrt{\varepsilon_{\text {eff }}}$, where $\varepsilon_{\text {eff }}$ and $\lambda_{o}$ are respectively the effective dielectric constant and the wavelength in free space [35]). Thus squinting radiation beams results especially around $9 \mathrm{GHz}$ frequencies. The same effect is noticeable for double-sided microstrip antennas [12-17] and single sided CPW-fed antennas [21-24].

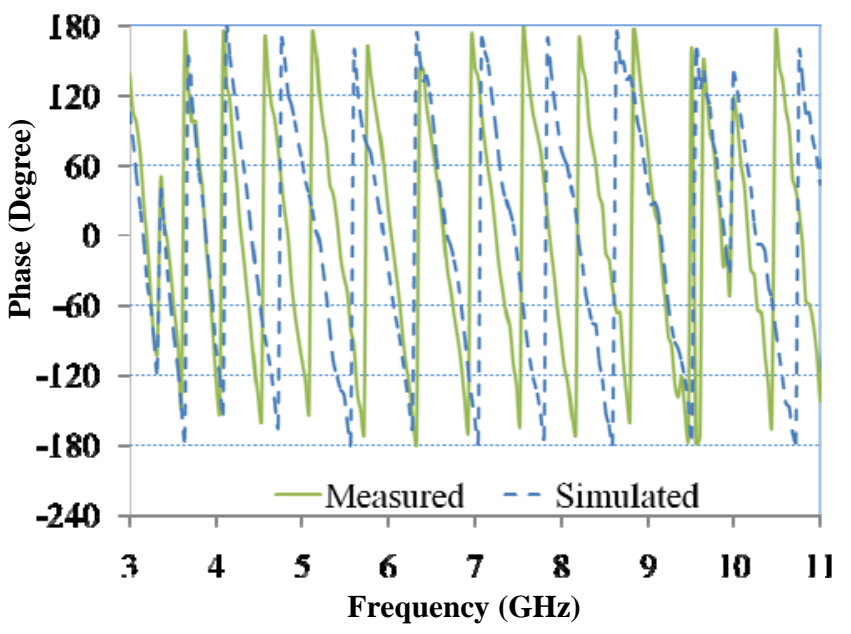

Fig.11. Measured and simulated phase distribution comparison of face-to-face orientation in far-field.

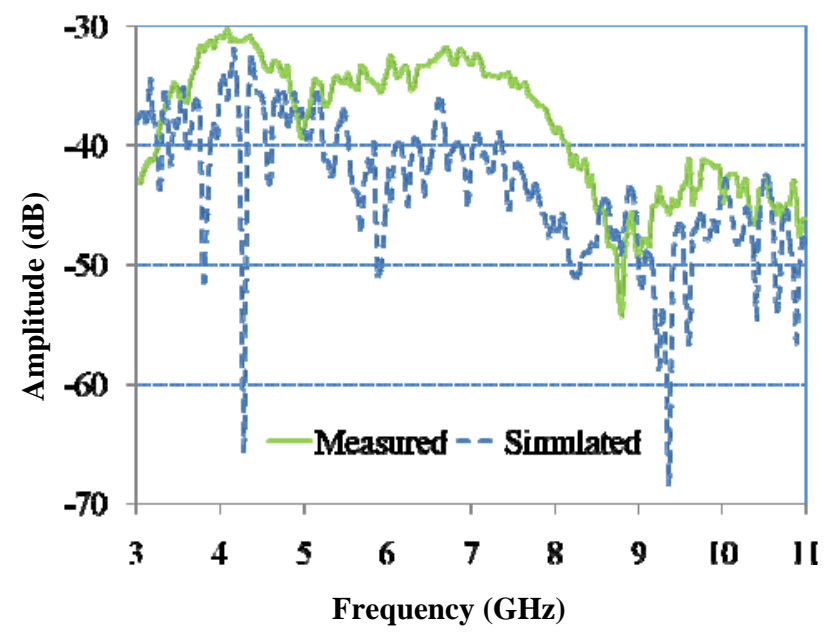

Fig.12. Measured and simulated magnitude response comparison of the transfer function. 
Group delay and phase response performance is essential for UWB, as it can be used to quantify the dispersion of the transmitted signals. In case of the narrow band antenna, these parameters are usually almost constant, but in ultra wideband frequency range they might vary significantly. Ideally, a constant or flat group delay (linear phase distribution) is desired to make the distortion of the transmitted pulse of the antenna is as low as possible. The group delay measurement is performed by exciting two identical prototypes of the antennas kept in the far field maintaining a distance of $1 \mathrm{~m}$ between them for face-to-face orientation in an anechoic chamber [37]. The simulated and measured group delay performance of the antenna shown Fig.10. It is observed that the transfer function of the designed antennas has a flat group delay and can be concluded that most of the portion of measured group delay is within $2.5 \mathrm{~ns}$. The simulated and measured phase distribution for the face-to-face orientation, shown in Fig.11., is also quite linear except in the high end of the operating frequencies. The better performance of the simulated result can be attributed to the less distorted ideal simulation environment. Fig.12. exhibits the measured and simulated magnitude versus frequency for a pair of proposed antennas for bore-sight radiation. The magnitude is fairly smooth in the working band with some exception (dented points) in the higher frequencies. This can be due to the losses or the shift in the radiation pattern of the antenna [33].

\section{ACKNOWLEDGEMENT}

The authors gratefully thank anonymous reviewers for their valuable suggestions to improve the quality of the manuscript and also Institute of Space Science (ANGKASA), Universiti Kebangsaan Malaysia, Bangi, Selangor, Malaysia, to facilitate the measurements needed for the proposed antenna.

\section{CONCLUSIONS}

A compact printed UWB antenna fed with CPW technique is presented in this paper for wireless applications. The proposed antenna consists of two asymmetric coplanar ground elements and a fed modified-bow-tie shaped radiating structure. The antenna is designed by MOM-based software IE3D and is verified by means of the prototype fabrication. The effect of the partial radiating ground plane was verified by simulated surface current distributions. The fabricated prototype provides a wideband operation of more than $8.7 \mathrm{GHz}$ (from $3.3 \mathrm{GHz}$ to more than $12 \mathrm{GHz}$ ). Besides its compact and ultra wideband characteristics, the proposed antenna features almost Omni-directional radiation patterns in both E- and H-planes over its operating frequencies with more than $0 \mathrm{dBi}$ peak gain. The antenna also provides good group delay, phase distribution and magnitude response of the antenna transfer function. Nevertheless, a comparison has been made between the measured and simulated results, which shows adequate resemblance between them. All these features of the proposed antenna make it a strong candidate for portable device applications.

\section{REFERENCES}

[1] Federal Communications Commission. (2002). First Report and Order in the Matter of Revision of Part 15 of the Commission's Rules Regarding Ultra-Wideband Transmission Systems. ET-Docket 98-153.

[2] Azim, R., Islam, M.T., Misran, N. (2011). Ground modified double-sided printed compact UWB antenna. Electronics Letters, 47 (1), 9-11.

[3] Cai, L.Y., Li, Y., Zeng, G., Yang, H.C. (2010). Compact wideband antenna with double-fed structure having band-notched characteristics. Electronics Letters, 46 (33), 1534-1536.

[4] Jung, E.-Y., Lee, J.W., Cho, C.S. (2010). Signal distortion analysis of L-shaped UWB antenna. IEEE Antennas and Wireless Propagation Letters, 9, 775778.

[5] Mobashsher, A.T., Islam, M.T., Misran, N. (2011). Loaded annular ring slot microstrip antenna for wideband and multi-band operation. Microwave Journal, 54 (9), 146-158.

[6] Azim, R., Mobashsher, A.T., Islam, M.T., Misran, N. (2010). Compact planar antenna for UWB applications. In 2010 International Conference on Microwave and Millimeter Wave Technology (ICMMT), 8-11 May 2010. IEEE, 1987-1990.

[7] Thomas, K.G., Sreenivasan, M. (2010). A simple ultrawideband planar rectangular printed antenna with band dispensation. IEEE Transactions on Antennas and Propagation, 58 (1), 27-34.

[8] Shambavi, K., Alex, Z.C. (2010). Printed dipole antenna with band rejection characteristics for UWB applications. IEEE Antennas and Wireless Propagation Letters, 9, 1029-1032.

[9] Azim, R., Islam, M.T., Mobashsher, A.T., Misran, N., Yatim, B. (2011). Compact printed ultra-wideband antenna with dual band- notch characteristics. In 14th International Conference on Computer and Information Technology (ICCIT), 22-24 December 2011. IEEE, 117-121.

[10] Mobashsher, A.T., Misran, N., Islam, M.T. (2011). Ultra-compact wideband antenna for portable device applications. Informacije MIDEM, 41 (3), 179-181.

[11] Medeiros, C.R., Costa, J.R., Fernandes, C.A. (2009). Compact tapered slot UWB antenna with WLAN band rejection. IEEE Antennas and Wireless Propagation Letters, 8, 661-664.

[12] Kiminami, K., Hirata, A., Shiozawa, T. (2004) Double-sided printed bow-tie antenna for UWB communications. IEEE Antennas and Wireless Propagation Letters, 3 (1), 152-153.

[13] Choi, S.H., Park, J.K., Kim, S.K., Park, J.Y. (2004). A new ultra-wideband antenna for UWB applications. Microwave and Optical Technology Letters, 40 (5), 399-401.

[14] Zaker, R., Ghobadi, C., Nourinia, J. (2008). Novel modified UWB planar monopole antenna with variable frequency band-notch function. IEEE Antennas and Wireless Propagation Letters, 7, 112-114. 
[15] Gayathri, R., Jisney, T.U., Krishna, D.D., Gopikrishna, M., Aanandan, C.K. (2008). Band-notched invertedcone monopole antenna for compact UWB systems. Electronics Letters, 44 (20), 1170-1171.

[16] Azim, R., Islam, M.T., Misran, N., Mobashsher, A.T. (2011). Compact UWB planar antenna for broadband applications. Informacije MIDEM, 41 (1), 37-40.

[17] Azim, R., Misran, N., Mobashsher, A.T., Islam, M.T. (2011). Compact planar antenna with dual bandnotched characteristics for UWB applications. In IEEE International Conference on Space Science and Communication (IconSpace), 12-13 July 2011. IEEE, 269-272.

[18] Mobashsher, A.T., Bais, B., Misran, N., Islam, M.T. (2010). Compact wideband microstrip antenna for universal $5 \mathrm{GHz}$ WLAN applications. Australian Journal of Basic and Applied Sciences, 4 (8), 34113417.

[19] Mobashsher, A.T., Islam, M.T., Misran, N. (2010). Wideband compact antenna with partially radiating coplanar ground plane. The Applied Computational Electromagnetics Society Journal, 26 (1), 73-81.

[20] Qing, X., Chen, Z.N. (2009). Compact coplanar waveguide-fed ultra-wideband monopole-like slot antenna. IET Microwaves, Antennas \& Propagation, 3 (5), 889-898.

[21] Yan, X.-R., Zhong, S.-S., Wang, G.-Y. (2008). Compact printed monopole antenna with 24:1 impedance bandwidth. Electronics Letters, 44 (2), 73 74.

[22] Lin, W.-P., Huang, C.-H. (2009). Coplanar waveguide-fed rectangular antenna with an inverted-L stub for ultrawideband communications. IEEE Antennas and Wireless Propagation Letters, 8, 228231.

[23] Zheng, Z.-A., Chu, Q.-X. (2009). CPW-fed ultrawideband antenna with compact size. Electronics Letters, 45 (12), 593-594.

[24] Xia, Y.Q., Duan, Z.G. (2008). Compact CPW-fed dual ellipses antenna for ultra-wideband system. Electronics Letters, 44 (9), 567.

[25] Ebrahimi, E., Litschke, O., Baggen, R., Hall, P.S. (2010). Isolation enhancement of planar disc antenna and ground plane in UWB applications. Electronics Letters, 46 (23), 1539-1541.

[26] Chamaani, S., Mirtaheri, S.A., Paran, K., Abolghasemi, A., Fardis, M. (2010). Coplanar waveguide-fed ultra wideband planar monopole antenna optimization. IET Microwaves, Antennas \& Propagation, 4 (9), 1264-1274.

[27] Tanyer-Tigrek, F.M., Hizal, A., Lager, I.E., Ligthart, L.P. (2010). On the operating principles of UWB, CPW-fed printed antennas. IEEE Antennas and Propagation Magazine, 52 (3), 46-50.

[28] Koohestani, M., Golpour, M. (2010). U-shaped microstrip patch antenna with novel parasitic tuning stubs for ultra wideband applications. IET Microwaves, Antennas \& Propagation, 4 (7), 938-946.
[29] Chen, M.-E., Wang, J.-H. (2008). CPW-fed crescent patch antenna for UWB applications. Electronics Letters, 44 (10), 613-614.

[30] Chen, S.-Y., Wang, P.-H., Hsu, P. (2006). Uniplanar log-periodic slot antenna fed by a CPW for UWB applications. IEEE Antennas and Wireless Propagation Letters, 5 (1), 256-259.

[31] Kim, Y., Kwon, D.-H. (2008). CPW-fed right-angled dual tapered notch antenna for ultra-wideband communication. Electronics Letters, 41 (12), 674-675.

[32] Joon I.K., Yong, J. (2007). Design of ultrawideband coplanar waveguide-fed LI-shape planar monopole antennas. IEEE Antennas and Wireless Propagation Letters, 6, 383-387.

[33] Yang, G.M., Jin, R.H., Xiao, G.B., Vittoria, C., Harris, V.G., Sun, N.X. (2009). Ultrawideband (UWB) antennas with multiresonant split-ring loops. IEEE Transactions on Antennas and Propagation, 57 (1), 256-260.

[34] Sze, J.-Y., Hsu, C.-I.G., Shiu, J.-Y. (2008). Small CPW-fed band-notched ultrawideband rectangular aperture antenna. IEEE Antennas and Wireless Propagation Letters, 7, 513-516.

[35] Mobashsher, A.T., Islam, M.T., Misran, N. (2011). Design and development of compact microstrip antennas for portable device applications. Informacije MIDEM, 41 (2), 105-113.

[36] Chen, H.-D. (2003). Broadband CPW-fed square slot antennas with a widened tuning stub. IEEE Transactions on Antennas and Propagation, 51 (8), 1982-1986.

[37] Cho, Y.J., Kim, K.H., Choi, D.H., Lee, S.S., Park, S.O. (2006). A miniature UWB planar monopole antenna with 5-GHz band-rejection filter and the timedomain characteristics. IEEE Transactions on Antennas and Propagation, 54 (5), 1453-1460.

[38] Azim, R., Islam, M.T., Misran, N. (2011). Design of a planar UWB antenna with new band enhancement technique. The Applied Computational Electromagnetics Society Journal, 26 (10), 856-862.

[39] Azim, R., Islam, M.T., Misran, N., Mandeep, J.S., Mobashsher, A.T. (2012). UWB antenna adds two notches. Microwaves and RF, 51 (12), 56-61.

[40] Azim, R., Mobashsher, A.T., Islam, M.T. (2013). UWB antenna with notched band at $5.5 \mathrm{GHz}$. Electronics Letters, 49 (15), 922-924.

[41] Liu, L., Cheung, S.W., Azim, R., Islam, M.T. (2011). A compact circular-ring antenna for ultra-wideband applications. Microwave and Optical Technology Letters, 53 (10), 2283-2288.

[42] Azim, R., Islam, M.T., Misran, N. (2010). Printed planar antenna for wideband applications. Journal of Infrared, Millimeter, and Terahertz Waves, 31 (8), 969-978.

Received January 7, 2013. Accepted July 31, 2013. 